\title{
DELAYED AND SELECTIVE MOTOR NEURON DEATH AFTER TRANSIENT SPINAL CORD ISCHEMIA: A ROLE OF APOPTOSIS?
}

Masahiro Sakurai, MD

Takeshi Hayashi, MD

Koji Abe, MD

Mitsuaki Sadahiro, MD

Koichi Tabayashi, MD
Objective: The mechanism of spinal cord injury has been thought to be related to tissue ischemia, and spinal motor neuron cells are suggested to be vulnerable to ischemia. We hypothesized that delayed and selective motor neuron death is apoptosis. Methods: Thirty-seven Japanese domesticated white rabbits weighing 2 to $3 \mathrm{~kg}$ were used in this study and were divided into two subgroups: a 15-minute ischemia group and a sham control group. Animals were allowed to recover at ambient temperature and were killed at 8 hours, and $1,2,4$, and 7 days after reperfusion ( $n=3$ at each time point). By means of this model, cell damage was histologically analyzed. Detection of ladders of oligonucleosomal DNA fragment was investigated with gel electrophoresis up to 7 days of the reperfusion. Immunocytochemistry, in situ terminal deoxynucleotidyl transferase-mediated deoxyuridine triphosphate-biotin nick-end labeling staining was also performed. Results: After 15 minutes of ischemia, most of the motor neurons showed selective cell death at 7 days of reperfusion. Typical ladders of oligonucleosomal DNA fragments were detected at 2 days of reperfusion. Immunocytochemistry showed in situ terminal deoxynucleotidyl transferase-mediated deoxyuridine triphosphate-biotin nick-end staining was detected at $\mathbf{2}$ days of reperfusion selectively in the nuclei of motor neurons. Conclusion: These results suggest that delayed and selective death of the motor neuron cells after transient ischemia may not be necrotic but rather predominantly apoptotic. (J Thorac Cardiovasc Surg 1998;115:1310-5)
$S_{\text {tit }}^{\text {p }}$ pinal cord injury after a successful operation on the thoracic aorta is a disastrous and unpredictable complication in human beings. The reported incidences of paraplegia range from $0.9 \%$ to $40 \%{ }^{1,2}$ in operations on the thoracic aorta. The cause of acute spinal cord dysfunction is believed to be due to spinal cord ischemia from hypoperfusion during crossclamping. Ischemia can occur because of permanent exclusion of the essential intercostal arterial blood supply to the spinal cord or by temporary interruption of blood flow to the spinal cord. ${ }^{3,4}$ However, patients undergoing thoracic aneurysm repair who awake with no neurologic deficit immediately after the operation may sometimes have

From the Department of Thoracic and Cardiovascular Surgery and the Department of Neurology, Tohoku University School of Medicine, Sendai, Japan.

Received for publication July 28, 1997; revisions requested Oct. 28, 1997; revisions received Dec. 30, 1997; accepted for publication Jan. 2, 1998.

Copyright (C) 1998 by Mosby, Inc.

$0022-5223 / 98 \$ 5.00+0 \quad \mathbf{1 2} / \mathbf{1} / \mathbf{8 8 6 8 1}$ eventual paraplegia develop days or weeks after the operation. ${ }^{5,6}$ In the rabbit spinal cord ischemia model we have reported delayed and selective motor neuron death after transient ischemia., 8 The exact mechanism of this phenomenon is not fully understood. To evaluate the mechanism of such vulnerability of motor neurons, we attempted to make a reproducible model for spinal cord ischemia and statistically analyze cell damage.

Recent studies have suggested that delayed neuronal death after transient ischemic injury in rat and gerbil brains has some apoptotic features. ${ }^{9-11}$ Apoptosis is associated with the activation of a genetic program in which apoptosis effector genes promote cell death. ${ }^{12,13}$ Apoptosis, a form of programmed cell death, plays a critical role in the regulation of development and maintenance of many tissues, including the central nervous system. ${ }^{14-16}$ Therefore we examined oligonucleosomal DNA fragment ladders by gel electrophoresis and in situ terminal deoxynucleotidyl transferase (TdT)-mediated deoxyuridine triphosphate (dUTP)-biotin nick-end labeling (TUNEL staining) after spinal cord ischemia 
for possible involvement of apoptosis in ischemic neuronal death.

\section{Materials and methods}

Animal models. Thirty-seven Japanese domesticated white rabbits weighing 2 to $3 \mathrm{~kg}$ were used in this study and were divided into two subgroups: a 15-minute ischemia group and a sham control group. Anesthesia was induced with intramuscular administration of ketamine at a dose of $50 \mathrm{mg} / \mathrm{kg}$ and maintained with $2 \%$ halothane inhalation. A $5 \mathrm{~F}$ pediatric thermodilution catheter (405, B. Braun Melsungen A.G., Germany) was inserted through a femoral artery and advanced $15 \mathrm{~cm}$ forward into the abdominal aorta. Preliminary investigations confirmed that the balloon in the distal end of the thermodilution catheter was positioned 0.5 to $1.5 \mathrm{~cm}$ just distal to the left renal artery. During the experiment, aortic pressures were continuously monitored at both the proximal and distal positions of the balloon. Body temperature was monitored with a rectal thermistor and was maintained at $37^{\circ} \mathrm{C}$ with the aid of a heating pad during operation and subsequent ischemia. Animals were allowed to recover at ambient temperature and were killed at 8 hours, and 1,2, 4, and 7 days after reperfusion ( $n=3$ at each time point). In the sham control $(n=3)$, animals were killed just after insertion of the catheter into abdominal aorta without inflating the balloon. Spinal cords were quickly removed immediately after death by use of the plunger of a $1 \mathrm{ml}$ syringe. ${ }^{17}$ The tissue samples for DNA and TUNEL staining were frozen in powdered dry ice and stored at $-80^{\circ} \mathrm{C}$. The samples for histologic examination were fixed by immersion in $4 \%$ paraformaldehyde in $0.1 \mathrm{~mol} / \mathrm{L}$ phosphate buffer and then stored at $4^{\circ} \mathrm{C}$ for 1 week; they were then cut transversely at about the L2 or L3 level and finally embedded in paraffin.

In the experiment, rabbits were treated in accordance with the Declaration of Helsinki and the Guiding Principles in the Care and Use of Animals. Also, the experimental and animal care protocol was approved by the Animal Care Committee of the Tohoku University School of Medicine.

Neurologic assessment. Neurologic function was observed at 8 hours, 1 day, 2 days, and 7 days after the procedure. Animals were classified with a five-point scale according to the method of Johnson, Kraimer, and Graeber ${ }^{18}$ : 0: hind-limb paralysis; 1: severe paraparesis; 2: functional movement, no hop; 3: ataxia, disconjugate hop; 4: minimal ataxia; 5: normal function. Two individuals without knowledge of the treatment graded neurologic function independently. Statistical analyses of the neurologic score were done with the Mann-Whitney U test.

Histologic study. The sections were stained with hematoxylin-eosin and examined by light microscopy. With hematoxylin-eosin staining the large motor neuron cells were considered necrotic if the cytoplasm was diffusely eosinophilic and viable if the cells demonstrated basophilic stippling (that is, contained Nissl substance). To determine the ischemic change, another series of animals was allowed to recover for 7 days after sham operation $(n=8)$ or 15 -minute ischemia $(n=10)$. The spinal cords were removed, fixed by immersion in $4 \%$ paraformalde-
Table I. Neurologic score at 2 days and 7 days after procedure

\begin{tabular}{cccc}
\hline & $\begin{array}{c}\text { Sham } \\
\text { control: }\end{array}$ & \multicolumn{2}{c}{15 -minute ischemia } \\
\cline { 3 - 4 } Animal No. & 7 days & 2 days & 7 days \\
\hline 1 & 5 & 5 & 3 \\
2 & 5 & 5 & 2 \\
3 & 5 & 5 & 2 \\
4 & 5 & 5 & 3 \\
5 & 5 & 4 & 2 \\
6 & 5 & 4 & 3 \\
7 & 5 & 4 & 3 \\
8 & 5 & 5 & 2 \\
9 & & 3 & 2 \\
10 & & 3 & 2 \\
Means \pm SEM & $5 \pm 0^{*}$ & $4.3 \pm 0.26 \dagger$ & $2.4 \pm 0.16$
\end{tabular}

Compared with the 15 -minute ischemia group at 7 days after procedure, ${ }^{*} p=0.0001 ; \dagger p=0.0003$.

hyde in $0.1 \mathrm{~mol} / \mathrm{L}$ phosphate buffer for 7 days, and then embedded in paraffin. The number of intact large motor neurons in Rexed's laminae VII, VIII, and IX was counted. Statistical analyses for the cell numbers were done with the Mann-Whitney U test.

Analysis of DNA fragmentation. The DNA was prepared according to the method of Linnik, Zobrist, and Hatfield. ${ }^{19}$ The spinal cords were minced, and cells were lysed on ice in $5 \mathrm{mmol} / \mathrm{L}$ Tris- $\mathrm{HCl}(\mathrm{pH} \mathrm{8.0)}$ containing 5 $\mathrm{mmol} / \mathrm{L}$ ethylenediaminetetraacetic acid and $0.5 \%$ Triton-X for 30 minutes. Genomic DNA was pelleted by centrifugation at $13,000 \mathrm{~g}$ for 20 minutes. DNA that did not sediment during centrifugation was purified by phenol/chloroform/isoamyl alcohol $(25: 24: 1)$ extraction and ethanol precipitation before RNase A digestion (100 $\mu \mathrm{g} / \mathrm{ml}$ ) for 30 minutes at $37^{\circ} \mathrm{C}$. Samples were then extracted again with chloroform/isoamyl alcohol (24:1) and reprecipitated in ethanol; DNA was separated on $2 \%$ agarose gel, visualized with ethidium bromide, and photographed under ultraviolet illumination.

TUNEL staining. To detect DNA fragmentation in nuclei of the cells, the modified TUNEL reaction was applied to the cryosections according to previous meth$\mathrm{od}^{20}$ using a kit (4810-30-K; Trevigen, Inc., Gaithersburg, Md.). Nuclei of tissue sections were stripped of proteins by incubation with $20 \mu \mathrm{g} / \mathrm{ml}$ proteinase $\mathrm{K}$ for 10 minutes. After being treated with $0.3 \% \mathrm{H}_{2} \mathrm{O}_{2}$ in distilled water for 5 minutes, they were incubated with TdT and biotinylated dUTP in TdT buffer in a humidified chamber at $37^{\circ} \mathrm{C}$ for 120 minutes. Further incubation with peroxidase-conjugated streptavidin was carried out for 30 minutes at room temperature. The slices were colorized with 3'3-diaminobenzidine $/ \mathrm{H}_{2} \mathrm{O}_{2}$ solution and then counterstained with methyl green.

\section{Results}

When the balloon of the thermodilution catheter was inflated in the abdominal aorta, systemic blood pressure of the rabbits did not change. The arterial pressure distal to the inflated balloon, on the other 

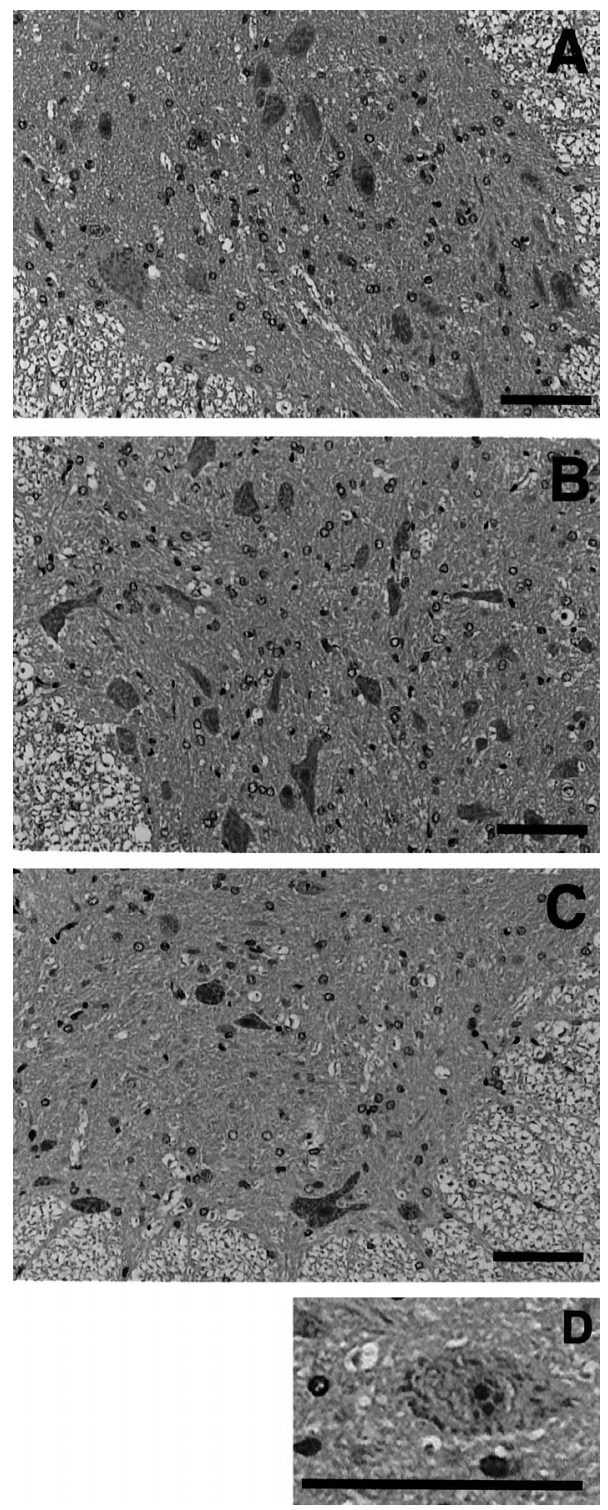

Fig. 1. Representative photographs of spinal cord sections stained with hematoxylin-eosin. No neuronal damage to any motor neuron cells was found in the sham control (A) and 2 days after 15-minute ischemia (B) groups. Seven days after 15 minutes of ischemia about $70 \%$ of motor neuron cells in ventral gray matter were lost (C). Four days after 15 minutes of ischemia apoptotic neurons exhibiting shrinkage, chromatin condensation, and nuclear budding were seen (D). Bar $=100 \mu \mathrm{m}$.

hand, fell to near zero and no pulse was recorded. On deflation of the balloon, systemic blood pressure of this portion decreased for 15 minutes and then returned to the normal level (data not shown). Spinal cord ischemia was achieved by inflating the
Table II. Numbers of large motor neurons in ventral gray matter at 2 days and 7 days after ischemia

\begin{tabular}{lcrc}
\hline \multicolumn{1}{c}{ Treatment of animals } & Date & No. & Cell numbers \\
\hline Sham & 7 days & 8 & $23 \pm 1.6^{*}$ \\
Sham + 15-min ischemia & 2 days & 10 & $21 \pm 2.1 \dagger$ \\
Sham + 15-min ischemia & 7 days & 10 & $7 \pm 1.9$ \\
\hline
\end{tabular}

Values are means \pm SEM.

Compared with the 15 -minute ischemia group at 7 days after procedure: ${ }^{*} p=0.0004 ; \dagger p=0.0016$.

balloon so as to obstruct blood flow to the spinal cord. ${ }^{21,22}$ The results obtained by gel electrophoresis, histocytochemical, and histologic studies were reproducible in animals at each time point.

Neurologic outcome. The results are summarized in Table I. In the sham operation group $(n=8)$ and in the 15-minute ischemia group at 8 hours $(n=3)$ and 1 day $(n=3)$ after the procedure, all rabbits were normal (grade 5). In the 15-minute ischemia group at 2 days after the procedure $(n=10)$, four rabbits $(40 \%)$ were normal (grade 5), four rabbits $(40 \%)$ had minimal ataxia (grade 4$)$, and two rabbits $(20 \%)$ had ataxia (grade 3 ). In the 15-minute ischemia group at 7 days after the procedure $(n=10)$, six rabbits $(60 \%)$ did not hop (grade 2) and four rabbits $(40 \%)$ had ataxia (grade 3 ). There was a significant difference between the Johnson neurologic scores at 2 days and at 7 days after the procedure in the 15-minute ischemia group ( $p=$ $0.0003)$. This difference was similarly marked between the sham control group and 15-minute ischemia group at 7 days after the procedure $(p=$ 0.0001 ). Fifteen minutes of ischemia did affect neuronal function.

Histologic study. Representative photographs of hematoxylin-eosin-stained sections are shown in Fig. 1. After sham control, no significant change was seen in motor neurons (Fig. 1, $A$ ). After 15 minutes of ischemia on the seventh day of reperfusion, about $70 \%$ of motor neuron cells in Rexed laminae VII, VIII, and IX were lost (Fig. 1, C), and some neuron cells were observed with necrotic characteristics, although most motor neuron cells had remained intact after 2 days of reperfusion $(p=0.0016)$. Small motor neurons and intermediate neurons survived the ischemia (Fig. 1, $B$ ). After 15 minutes of ischemia on the fourth day of reperfusion, apoptotic motor neurons exhibited shrinkage, chromatin condensation, and nuclear budding (Fig. 1, D). Dorsal horn neurons were intact after 15 minutes of ischemia at any time point (data not shown). The results of cell counting in the ventral gray 


\section{S 8h 1d 2d}

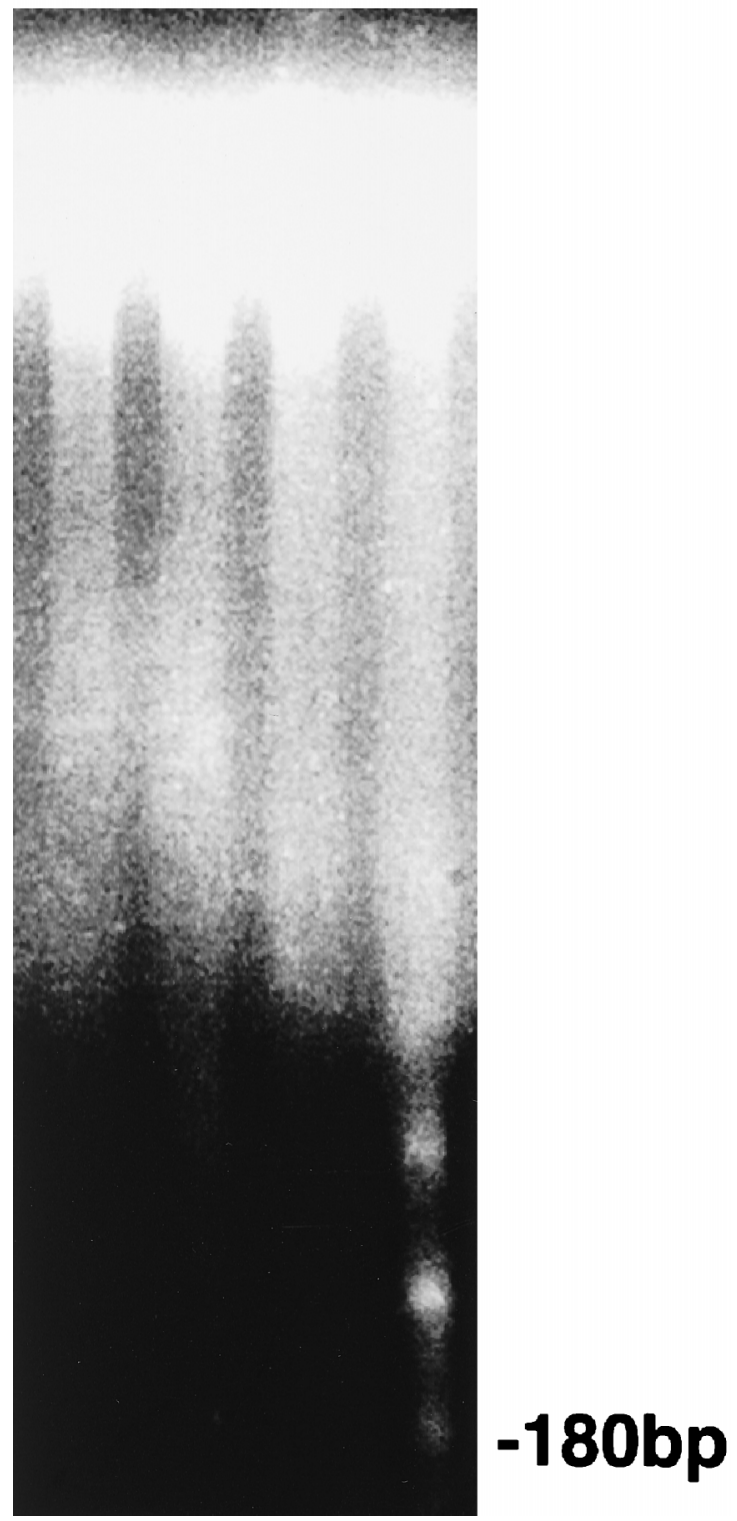

Fig. 2. Gel electrophoresis of the genomic DNA in rabbit spinal cord of the sham control group $(S)$ and postischemic spinal cords at 8 hours $(8 h), 1$ day (1d), and 2 days (2d) after reperfusion. A ladder of DNA fragmentation into oligonucleosomal fragments appears in the tissue 2 days after the ischemic insult. $b p$, Base pair.

matter region on the paraffin sections obtained from another series of animals are shown in Table II. The 15-minute ischemic period at 7 days after the procedure affected the number of motor neuronal loss cells in contrast to sham control $(p=0.0004)$.

Analysis of DNA fragmentation. Fig. 2 shows the
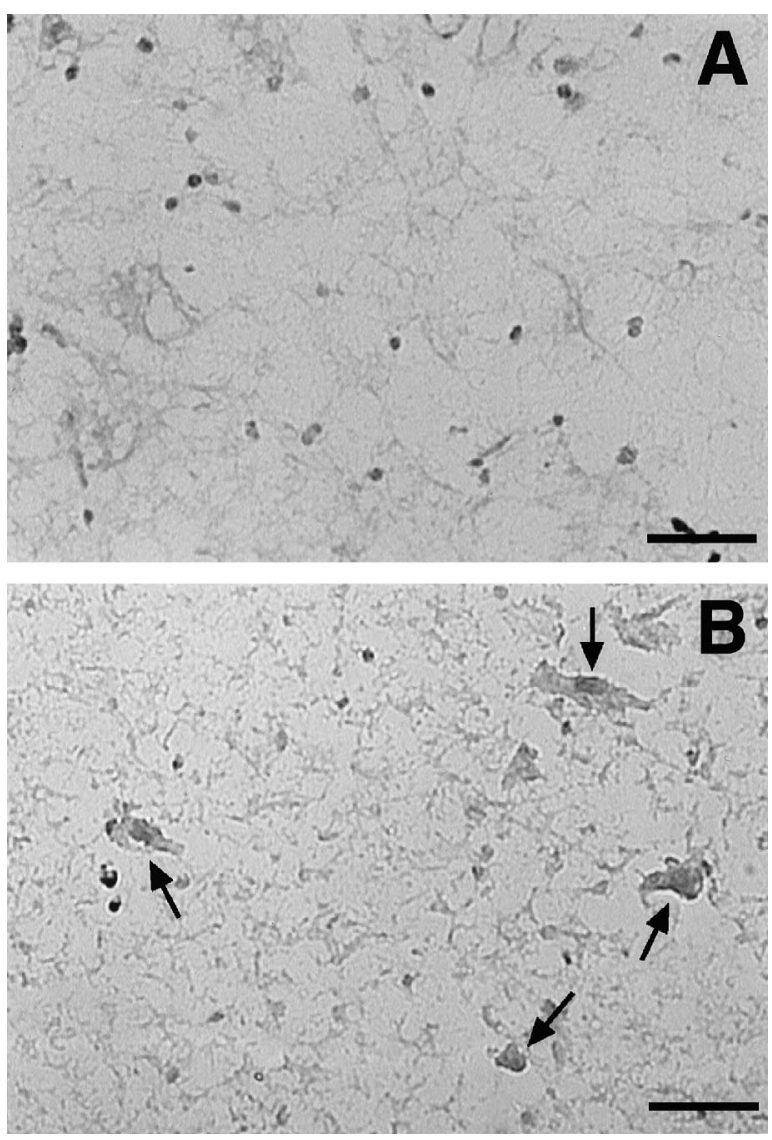

Fig. 3. TUNEL staining in the ventral gray matter of a sham spinal cord (A) and at 2 days of reperfusion after 15 minutes of ischemia (B). Arrows show motor neuron cell nuclei that are positive with TUNEL staining. Bar $=100$ $\mu \mathrm{m}$.

Table III. Change in DNA fragmentation in the spinal cord after transient ischemia

\begin{tabular}{cccccccc}
\hline & Sham & $8 \mathrm{hr}$ & 1 day & 2 days & 4 days & 7 days \\
\hline DNA fragmentation & - & - & - & + & - & - \\
& - & - & - & + & - & - \\
& - & - & - & + & - & -
\end{tabular}

Signal intensities of DNA fragmentation was rated as follows: negative $(-)$; positive $(+)$.

results of DNA fragmentation. The bulk of the genomic DNA extracted from the sham control animals demonstrated that the integrity of DNA was preserved after gel electrophoresis. After $15 \mathrm{~min}$ utes of ischemia, several patterns of DNA were observed: no DNA degradation for 8 hours and 1 day of reperfusion; and a typical DNA ladder pattern with oligonucleosome-sized to 180 base pair 
fragments at 2 days of reperfusion; a smear pattern suggesting random DNA degradation at 4 and 7 days of reperfusion (data not shown).

TUNEL staining. TUNEL staining of the spinal cords is shown in Fig. 3. Positive staining of the TUNEL reaction was not detected in nuclei of the motor neurons by both 8 hours and 1 day after the ischemic insult in those obtained in the shamoperated control spinal cords (Fig. 3, A). Two, 4, and 7 days after the ischemic insult, positive staining in the motor neuron cells in Rexed laminae VII, VIII, and IX were detected $(6.67 \pm 0.88,3.33 \pm$ 0.88 , and $2.67 \pm 0.33$, respectively) (Fig. 3, $B$, arrows), but neurons in the dorsal horn of the gray matter and white matter did not react to TUNEL staining. The motor neurons with positive-stained nuclei were detected even 7 days after ischemic impact, although $70 \%$ of motor neurons distinctly decreased in the ventral gray matter.

\section{Discussion}

We have demonstrated delayed and selective motor neuron death in lumbar regions of the rabbit spinal cord with a reproducible model. The neurologic and histologic patterns of the 15-minute ischemia group in our models are reproducible. Analysis of DNA fragmentation was also reproducible at each time point (Table III).

We have previously demonstrated delayed and selective motor neuron death in lumbar regions of the rabbit spinal cord with a reproducible model..$^{7,8}$ Fifteen minutes of ischemia is a relatively short ischemic period compared with those of previously reported models, ${ }^{18}$ and after the ischemia, delayed and selective motor neuron damage was observed only after 7 days of reperfusion in this model. This phenomenon is known as selective neuronal death in motor neuron cells after spinal cord ischemia. ${ }^{23}$ Despite recovery of blood flow, ${ }^{24}$ motor neurons, which initially appear to have survived ischemic insult, go on to die days later. This result is associate with delayed deterioration of neurologic function after spinal cord ischemia.

It is known that two major forms of cell death, necrosis and apoptosis, have been distinguished morphologically, ${ }^{25,26}$ although absolute criteria for distinction has not been delineated. ${ }^{27}$ Necrosis is characterized by prominent acute cell body swelling with subsequent cell lysis. Apoptosis is characterized by compaction of the cell body and internucleosomal DNA fragments. TUNEL reaction is based on the specific binding of TdT to $3^{\prime}$-hydroxy termini of
DNA, ensuing synthesis of a biotinylated polydeoxynucleotide polymer. ${ }^{20}$ Obviously, fragmentation of nuclear DNA also occurs in necrosis. Because DNA is degraded by nonspecific lysosomal DNases in necrotic cells, these cells are supposed to be stained as well. However, because of nonspecificDNA cleavage, necrotic nuclei might not exhibit a stainable concentration of 3 '-hydroxy termini of DNA. A previous report showed that necrosis in glioblastoma sections was unstained by the TUNEL method. ${ }^{28}$

The DNA ladder pattern with oligonucleosomesized fragments of $180 \mathrm{bp}$ by gel electrophoresis is commonly considered to be a useful biochemical hallmark of apoptosis. ${ }^{29}$ The selective detection of DNA fragmentation in motor neuron cells at a stage of absent neuronal loss at 2 days may indicate that the apoptotic change is occurring in the spinal cord after 15 minutes of ischemia, and finally, about $70 \%$ of motor neurons were selectively damaged after 7 days of reperfusion. We present here our initial support, on the basis of the observed data, for the possibility that cell death may predominantly be due to apoptosis. This is the first study that demonstrates a role for apoptosis in delayed paraplegia.

In the gerbil brain the CA1 cells of the hippocampus are selectively vulnerable to ischemia and undergo cell death several days after transient forebrain ischemia. ${ }^{30}$ Recent studies have shown that delayed neuronal death in the CA1 cells of the hippocampus after transient ischemia has some of the same features as apoptosis. ${ }^{11-14}$ Thus our result suggests that delayed and selective motor neuron death after transient ischemia are consistent with the biochemical criteria of apoptosis. Therefore the mechanism of cell injury of the motor neurons in the spinal cord and the hippocampal cells of the brain after ischemia may be similar.

This study demonstrated that delayed and selective death of the motor neuron cells after transient ischemia in the spinal cord may not be necrotic but rather predominantly apoptotic.

We thank T. Sato, K. Itagaki, and K. Katusrada for their excellent technical assistance.

REFERENCES

1. Crawford ES, Waler HS, Saleh SA, Normann NA. Graft replacement of aneurysm in descending thoracic aorta: results without shunting. Surgery 1981;89:73-85.

2. Crawford ES, Crawford JL, Sail HJ, Coselli JS, Hess KR, Brooks B. Thoracoabdominal aortic aneurysms: preoperative and intraoperative factors determining immediate and long- 
term results of operations in 605 patients. J Vasc Surg 1986;3:389-404.

3. Kats NM, Blackstone EH, Kirklin JW, Karp RB. Incremental risk factors for spinal cord injury following operation for acute aortic transection. J Thorac Cardiovasc Surg 1981;81: 669-74.

4. Livesay JJ, Cooley DA, Ventemiglia RA, Ventemiglia RA, Montero CG, Warrian RK, et al. Surgical experience in descending thoracic aneurysmectomy with and without adjuncts to avoid ischemia. Ann Thorac Surg 1985;39:37-46.

5. Moore WM, Hollier LY. The influence of severity of spinal cord ischemia in the etiology of delayed-onset paraplegia. Ann Surg 1991;213:427-32.

6. Matsui Y, Goh K, Shinya N, Murashita T, Miyama M, Ohbata J, et al. Clinical application of evoked spinal cord potentials elicited by direct stimulation of the cord during temporary occlusion of the thoracic aorta. J Thorac Cardiovasc Surg 1994;107:1519-27.

7. Watanabe M, Sakurai M, Abe K, Aoki M, Sadahiro M, Tabayashi $\mathrm{K}$, et al. Inductions of $\mathrm{Cu} / \mathrm{Zn}$ superoxide dismutase- and nitric oxide synthase-like immunoreactivities in rabbit spinal cord after transient ischemia. Brain Res 1996; 732:69-74.

8. Sakurai M, Aoki M, Abe K, Sadahiro M, Tabayashi K. Selective motor neuron death and heat shock protein induction after spinal cord ischemia in rabbits. J Thorac Cardiovasc Surg 1997;113:159-64.

9. Nitatori T, Sato N, Waguri S, Karasawa Y, Araki H, Shibanai $\mathrm{K}$, et al. Delayed neuronal death in the CA1 pyramidal cell layer of the gerbil hippocampus following transient ischemia is apoptosis. J Neurosci 1995;15:1001-11.

10. Héron A, Pollard H, Dessi F, Moreau J, Lasbennes F, Ben-Ari Y, et al. Regional variability in DNA fragmentation after global ischemia evidenced by combined histological and gel electrophoresis observations in the rat brain. J Neurochem 1993;61:1973-6.

11. Li Y, Chopp M, Yao F, Zaloga C. Temporal profile of in situ DNA fragmentation after transient middle cerebral artery occlusion in the rat. J Cereb Blood Flow Metab 1995;15:38997.

12. Hockenbery D, Nunez G, Milliman C, Schreiber RD, Koesmeyer SJ. Bcl-2 is an inner mitochondrial membrane protein that blocks programmed cell death. Nature 1990;348:334-6.

13. Sentman CL, Shutter JR, Hockenbery D, Kanagawa O, Korsmeyer SJ. Bcl-2 inhibits multiple forms of apoptosis but not negative selection in thmocytes. Cell 1991;67:879-88.

14. Johnson EM, Greenlund LJ, Hus CY. Neuronal apoptosis: current understanding of molecular mechanisms and potential role in ischemic brain injury. J Neurotrauma 1995;5:84352.
15. Rink A, Fung KM, Trojanowski JQ, Lee VMY, Neugebauer E, Mclntosh TK. Evidence of apoptotic cell death after experimental traumatic brain injury in the rat. Am J Pathol 1995;147:1575-83.

16. Saunders JJ. Death in embryonic systems. Science 1966;154: 604-12.

17. Zivin JA, Reid JL, Saavedra JM, Kopin IJ. Quantitative localization of biogenic amines in the spinal cord. Brain Res 1975;99:293-01.

18. Johnson SH, Kraimer JM, Graeber GM. Effect of flunarizine on neurological recovery and spinal cord blood flow in experimental spinal cord ischemia in rabbits. Stroke 1993;24: 1547-53.

19. Linnik MD, Zobrist RH, Hatfield MD. Evidence supporting a role for programmed cell death in focal cerebral ischemia in rats. Stroke 1993;24:2002-8.

20. Gavrieli Y, Sherman Y, Ben-Sasson SA. Identification of programmed cell death in situ via specific labeling of nuclear DNA fragmentation. J Cell Biol 1992;119:493-501.

21. Cheng MK, Robertson C, Grossman RG, Folitz R, Williams V. Neurological outcome correlated with spinal evoked potentials in a spinal cord ischemia model. J Neurosurg 1984; 60:786-95.

22. Herold JA, Kron IL, Langenburg SE, Blackbourne LH, Tribble CG. Complete prevention of postischemic spinal cord injury by means of regional infusion with hypothermic saline and adenosine. J Thorac Cardiovasc Surg 1994;107: $536-42$.

23. DeGirolami U, Zinvin JA. Neuropathology of experimental spinal cord ischemia in the rabbit. J Neuropathol Exp Neurol 1982;41:129-49.

24. Jacobs TP, Kempski O, McKinley D, Dutka AJ, Hallenbeck JM, Feuerstein G. Blood flow and vascular permeability during motor dysfunction in a rabbit model of spinal cord ischemia. Stroke 1992;23:367-73.

25. Kerr JF, Wyllie AH, Currie AR. Apoptosis: a basic biological phenomenon with wide-ranging implications in tissue kinetics. Br J Cancer 1972;26:239-57.

26. Wyllie AH, Kerr JF, Currie AR. Cell death: the significance of apoptosis. Int Rev Cytol 1980;23:251-306.

27. Eaber E. Programmed cell death: necrosis versus apoptosis. Mod Pathol 1994;7:605-7.

28. Kihara S, Shiraishi T, Nakagawa S, Toda K, Tabuchi K. Visualization of DNA double strand breaks in the gerbil hippocampal CA1 following transient ischemia. Neurosci Lett 1994;175:133-6.

29. Arends MJ, Wyllie AH. Apoptosis: mechanisms and roles in pathology. Int Rev Exp Pathol 1991;32:223-54.

30. Kirino T. Delayed neuronal death in the gerbil hippocampus following ischemia. Brain Res 1982;239:209-18. 